University of Nebraska - Lincoln

DigitalCommons@University of Nebraska - Lincoln

U.S. Department of Veterans Affairs Staff

Publications

U.S. Department of Veterans Affairs

$6-2008$

\title{
Proteasome Activation by Hepatitis C Core Protein Is Reversed by Ethanol-Induced Oxidative Stress
}

\author{
Natalia A. Osna \\ Omaha Veterans Affairs (VA) Medical Center, natalia_osna@hotmail.com \\ Ronda L. White \\ University of Nebraska Medical Center \\ Viatcheslav M. Krutik \\ University of Nebraska Medical Center \\ Ting Wang \\ University of Texas Medical Branch \\ Steven A. Weinman \\ University of Texas Medical Branch, sweinman@kumc.edu \\ See next page for additional authors
}

Follow this and additional works at: https://digitalcommons.unl.edu/veterans

Osna, Natalia A.; White, Ronda L.; Krutik, Viatcheslav M.; Wang, Ting; Weinman, Steven A.; and Donohue, Terrence M. Jr, "Proteasome Activation by Hepatitis C Core Protein Is Reversed by Ethanol-Induced Oxidative Stress" (2008). U.S. Department of Veterans Affairs Staff Publications. 61.

https://digitalcommons.unl.edu/veterans/61

This Article is brought to you for free and open access by the U.S. Department of Veterans Affairs at DigitalCommons@University of Nebraska - Lincoln. It has been accepted for inclusion in U.S. Department of Veterans Affairs Staff Publications by an authorized administrator of DigitalCommons@University of Nebraska - Lincoln. 
Authors

Natalia A. Osna, Ronda L. White, Viatcheslav M. Krutik, Ting Wang, Steven A. Weinman, and Terrence M. Donohue Jr 


\title{
Proteasome Activation by Hepatitis C Core Protein Is Reversed by Ethanol-Induced Oxidative Stress
}

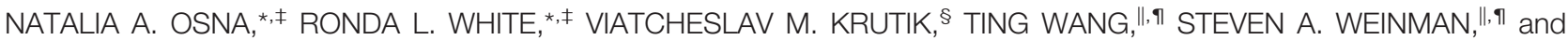 \\ TERRENCE M. DONOHUE Jr,
}

*Liver Study Unit, Omaha Veterans Affairs (VA) Medical Center, ${ }^{\ddagger}$ Department of Internal Medicine, and ${ }^{\S}$ Department of Bioinformatics Core Facility, Eppley Institute, University of Nebraska Medical Center, Omaha, Nebraska; "Department of Neuroscience and Cell Biology and "Department of Internal Medicine, University of Texas Medical Branch, Galveston, Texas

Background \& Aims: The proteasome is a major cellular proteinase. Its activity is modulated by cellular oxidants. Hepatitis $\mathrm{C}$ core protein and ethanol exposure both cause enhanced oxidant generation. The aim was to investigate whether core protein, by its ability to generate oxidants, alters proteasome activity and whether these alterations are further affected by ethanol exposure. Methods: These interactions were examined in Huh-7 cell lines that expressed inducible HCV core protein and/or constitutive cytochrome P450 2E1 (CYP2E1) and as purified components in a cell-free system. Chymotrypsin-like proteasome activity was measured fluorometrically. Results: Proteasome activity in core-positive 191-20 cells was $20 \%$ higher than that in core-negative cells and was enhanced 3-fold in CYP2E1-expressing L14 cells. Exposure of core-positive cells to glutathione ethyl ester, catalase, or the CYP2E1 inhibitor diallyl sulfide partially reversed the elevation of proteasome activity in core-positive cells, whereas ethanol exposure suppressed proteasome activity. The results indicate that proteasome activity was up-regulated by low levels of core-induced oxidative stress but downregulated by high levels of ethanol-elicited stress. These findings were partially mimicked in a cell-free system. Addition of core protein enhanced the peptidase activity of purified $20 \mathrm{~S}$ proteasome containing the proteasome activator PA28 and was further potentiated by addition of liver mitochondrial and/or microsome fractions. However, proteasome activation was significantly attenuated when fractions were obtained from ethanol-fed animals. Conclusions: HCV core protein interacts with PA28, mitochondrial, and endoplasmic reticulum proteins to cause low levels of oxidant stress and proteasome activation, which is dampened during ethanol metabolism when oxidant generation is higher.

$\mathrm{T}$ he proteasome is the major cellular protein-degrading enzyme that degrades $80 \%$ of intracellular proteins. The enzyme is crucial for cell survival because it plays a pivotal role in destroying not only normal but also damaged proteins. By degrading short-lived signal transduction factors, the proteasome regulates signal transduction events and the inflammatory response., ${ }^{1,2}$ In the immune response, the proteasome cleaves antigenic proteins to generate peptides for major histocompatibility complex (MHC) class I-restricted antigen presentation. ${ }^{3}$

Proteasome function is regulated by the levels of intracellular oxidants. In liver cells, the proteasome is continuously exposed to oxidants because of mitochondrial electron transport as well as high expression levels of cytochrome P4502E1 (CYP2E1). Multiple agents, including viral proteins and ethanol, enhance oxidant generation in the liver.

Hepatitis $\mathrm{C}$ virus (HCV) core protein plays an important role in $\mathrm{HCV}$ infection pathogenesis. The viral protein is known to induce oxidative stress by its ability to associate with the outer membrane of the mitochondrion. This interaction increases $\mathrm{Ca}^{2+}$ entry, mitochondrial superoxide production, and subsequently elevates generation of reactive oxygen species (ROS) by mitochondrial electron transport complex I. This results in a decreased mitochondrial glutathione (GSH) and in mitochondrial depolarization, which can be augmented by simultaneous endoplasmic reticulum (ER) oxidative stress. ${ }^{4,5}$ The ability of core protein to increase oxidant production has been reported in isolated mitochondria, in cells expressing core protein, in full-length HCV replicon, and in liver mitochondria derived from HCV transgenic mice. ${ }^{5,6}$ These effects of core protein are enhanced in CYP2E1-expressing cells and are further potentiated by alcohol exposure. ${ }^{4-7}$ Because core protein induces oxidant formation and because the proteasome is sensitive to their levels in cells, ${ }^{8-10}$ we postulated that core protein up-regulates proteasome activity. Further induction of oxidative stress by ethanol exposure may revise the effects

Abbreviations used in this paper: CYP2E1, cytochrome P450 2E1; DAS, diallyl sulfide; ER, endoplasmic reticulum; GSH-EE, glutathione ethyl ester; HCV, hepatitis C virus; HSP, heat shock protein; ROS, reactive oxygen species; t- $\mathrm{BOOH}$, t-butyl hydroperoxide.

(C) $\mathbf{2 0 0 8}$ by the AGA Institute 0016-5085/08/\$34.00 doi:10.1053/j.gastro.2008.02.063 
of core protein on proteasome because ethanol metabolism suppresses proteasome activity. ${ }^{11,12}$ Suppression of proteasome activity may enhance disease progression in $\mathrm{HCV}$-infected, alcohol-consuming patients because it is known that ethanol consumption exacerbates the clinical course of HCV infection in these individuals. ${ }^{13,14}$ To date, specific interactions between proteasome and HCV core protein and the effects of ethanol on these interactions have not been investigated. Hence, we sought to determine specific interactions between HCV core protein and proteasome activity in vitro and in cultured hepatoma cells that have inducible expression of $\mathrm{HCV}$ core protein and in cells with and without constitutive expression of CYP2E1.

\section{Materials and Methods}

\section{Reagents and Media}

High-glucose Dulbecco's modified Eagle medium (DMEM), F12, blasticidin S, and fetal bovine serum (FBS) were purchased from Invitrogen (Carlsbad, CA). G418 and antibody to PA28 $\alpha$ were from Calbiochem (La Jolla, CA). MeO-Suc-Phe-Leu-Phe-AFC (FLF-AFC) was from MP Biomedicals (Aurora, $\mathrm{OH}$ ). Other reagents, all of analytical grade quality, were from Sigma Chemical Co (St Louis, MO). PA28 was a gift from Dr George DeMartino, University of Texas Southwestern Medical Center, Dallas, TX.

\section{Cell Lines}

Huh7 cells, which express core protein under a tetracycline-repressible promoter, either in CYP2E1-nonexpressing (191-20) or in CYP2E1-expressing (L-14) cell lines were used in this study. Both cell lines expressed core protein in the absence of tetracycline after 4 days of tetracycline withdrawal and exhibited no core expression in its presence at $2 \mu \mathrm{g} / \mathrm{mL}$ (Figure $1 A$ ). Both core protein and CYP2E1 were detected by Western blot using monoclonal anti-HCV core (Affinity BioReagents, Golden, $\mathrm{CO}$ ) or anti-CYP2E1 (Calbiochem, La Jolla, CA), respectively. Culture conditions were as described. ${ }^{7}$

\section{Cell Treatments}

Hepatoma cells were plated onto 96-well black plates with clear bottoms at a density of $5 \times 10^{3}$ cells/ well and were incubated in a 1:1 mixture of DMEM/F12, media supplemented with 5\% FBS, penicillin-streptomycin, and selective antibiotics $(200 \mu \mathrm{g}$ G $418 / \mathrm{mL}$ for the core protein and $4 \mu \mathrm{g}$ blasticidin $\mathrm{S} / \mathrm{mL}$ for the CYP2E1 expression). After overnight attachment, cells were treated as described in the text and Figure legends.

\section{Proteasome Purification}

$20 \mathrm{~S}$ proteasome was purified from rat livers according to the procedure described..$^{15}$ The purification steps included a high-speed $(105,000 \mathrm{~g})$ centrifugation for 60 minutes followed by a 16-hour centrifugation of the
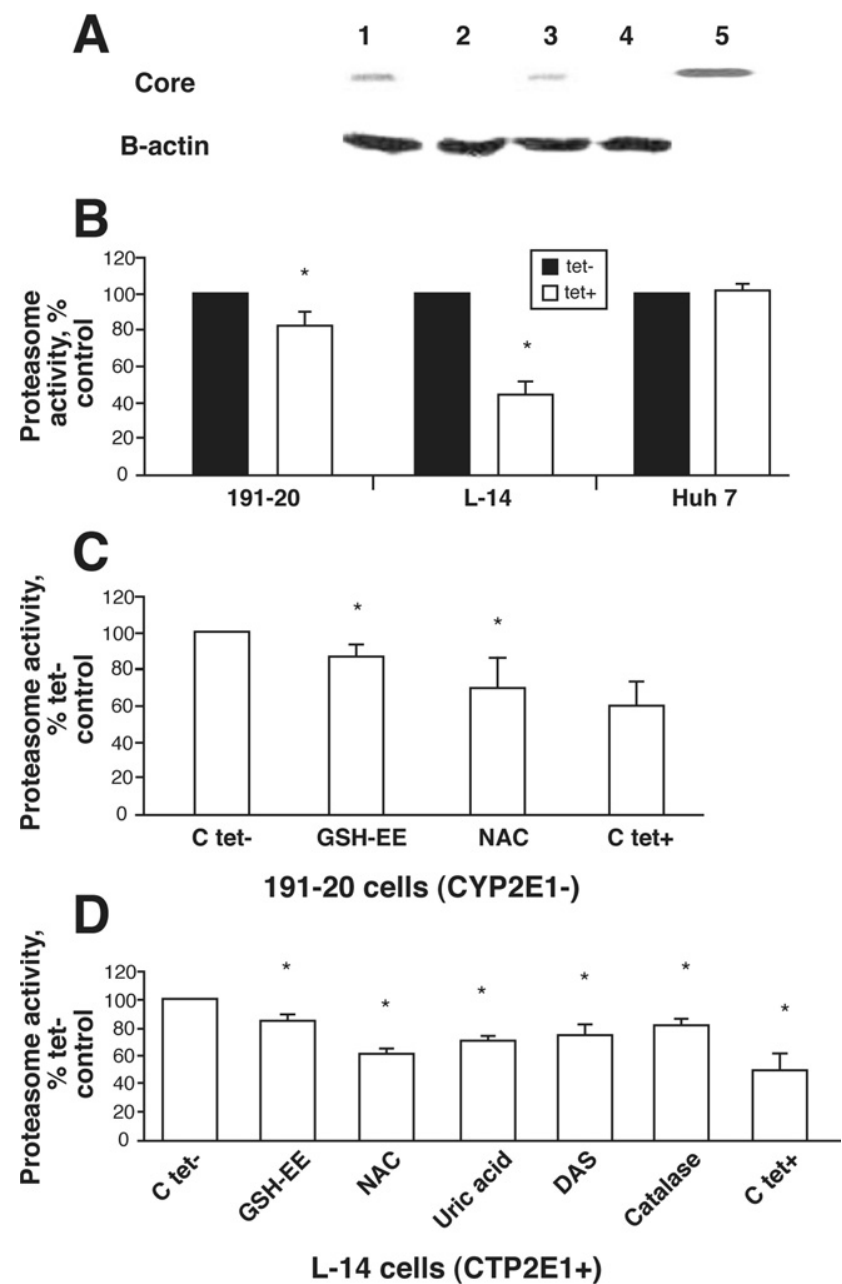

Figure 1. (A) Expression of core protein in tet ${ }^{-}$and tet ${ }^{+}$Huh7 cells. HCV core protein was detected in cell lysates by Western blot, and $\beta$-actin was used as a loading control: 1. 191-20 tet ${ }^{-}$cells; 2. 191-20 tet $^{+}$cells; 3. L-14 tet ${ }^{-}$cells; 4. L-14 tet $^{+}$cells; 5. Recombinant HCV core protein. (B) Proteasome activity in 191-20, L-14, and Huh7 cells before and after tetracycline treatment. All 3 cell lines were treated or not with $2 \mu \mathrm{g}$ tetracycline/ml for 4 days. Core protein was detected only in cell lysates of tet ${ }^{-} 191-20$ and L-14 cells by Western blot (insert above each bar). Proteasome activity is expressed as percent of control. Percent of control is calculated as (proteasome activity in all experimental readings expressed as (nmol AFC/ $\mu \mathrm{g}$ DNA divided by nmol $\mathrm{AFC} / \mu \mathrm{g}$ DNA proteasome activity in untreated tet ${ }^{-}$cells) $\times 100 \%$. Data are mean values \pm SD from 3 experiments. *Indicates a significant difference $(P<.05)$ between tet ${ }^{-}$control cells and other treatments. $(C)$ Proteasome activity in 191-20 cells. Tetracycline-untreated cells were treated with $5 \mathrm{mmol} / \mathrm{L}$ GSH-EE, $20 \mathrm{mmol} / \mathrm{L}$ N-acetyl cysteine (NAC), or $1000 \mathrm{U}$ catalase for 24 hours. Proteasome activity was detected by in situ assay and compared with that in 191-20 tetracycline-treated cells. Data from 4 independent experiments are expressed as percent proteasome activity in control in tetracycline-untreated cells. *Indicates a significant difference $(P<.05)$ between tet $^{-}$control cells and other treatments. $(D)$ Proteasome activity in $L-14$ cells. $L-14$ cells were treated just as described in $A$ with $20 \mu \mathrm{mol} / L$ DAS and $100 \mu \mathrm{mol} / \mathrm{L}$ uric acid for 24 hours. Data from 4 independent experiments are expressed as percent of control proteasome activity in tetracycline-untreated cells. ${ }^{*}$ Indicates a significant difference between tet ${ }^{-}$control cells and other treatments. 
cytosol at $52,000 \mathrm{~g}$, DEAE-Sepharose chromatography of the resuspended proteasome pellet, and hydrophobic interaction chromatography on a phenyl-sepharose column. In addition to the above-described purification, the residual enzyme remaining in high-speed supernatant fraction (which was enriched with PA28) was purified as described. ${ }^{16}$

\section{HCV Core Protein Purification}

Cloning, expression, and purification of HCV core protein were performed as described by Kunkel et al. ${ }^{17,18}$ Briefly, HCV core residues 1 to 179 (HCVC 179) derived from the AG94 isolate of genotype 1a sequence was amplified by polymerase chain reaction (PCR) and cloned into a pET30a expression vector (Novagen, Gillstown, $\mathrm{NJ})$. Core protein was expressed by transforming Escherichia coli BL21 (DE3) cells with the expression vector. Expression was induced by addition of $1 \mathrm{mmol} / \mathrm{L}$ isopropyl- $\beta$-D thiogalactopyranoside. The cells were solubilized by sonication. Lysates were then diluted with $8 \mathrm{~mol} / \mathrm{L}$ urea and incubated overnight at $4^{\circ} \mathrm{C}$ with $50 \mathrm{mmol} / \mathrm{L}$ dithiothreitol. The supernatant was applied to a cationexchange column (Poros $20 \mathrm{CM}$ ) preequilibrated with $0.25 \mathrm{~mol} / \mathrm{L}$ HEPES, pH 7.0, $8 \mathrm{~mol} / \mathrm{L}$ urea, and $1.5 \mathrm{~mol} / \mathrm{L}$ $\mathrm{NaCl}$. Each fraction was separated by SDS-PAGE, and the gels were stained with coomassie blue to identify HCVC 179 , which was found in a single peak eluting around 650 $\mathrm{mmol} / \mathrm{L} \mathrm{NaCl}$. These fractions were subsequently subjected to reverse-phase, high-pressure liquid chromatography (YMC-ODS column; reverse-phase, $150 \times 4.6 \mathrm{~mm}$ ) and eluted with a linear gradient of $20 \mathrm{mmol} / \mathrm{L}$ sodiumphosphate-methanol, pH 3.0. Fractions were analyzed as describe above. Eluted fractions containing core protein were pooled and dialyzed overnight at $4^{\circ} \mathrm{C}$ against refolding buffer $(20 \mathrm{mmol} / \mathrm{L}$ Tris [pH 7.0], $100 \mathrm{mmol} / \mathrm{L}$ $\mathrm{NaCl}$ ). Proteinase inhibitors were added to the dialyzed sample $(50 \mu \mathrm{mol} / \mathrm{L}$ leupeptin, $1 \mu \mathrm{mol} / \mathrm{L}$ pepstatin $\mathrm{A}$, and $0.5 \mathrm{mmol} / \mathrm{L}$ phenylmethylsulfonyl fluoride). The homogeneity of purified core protein was determined by SDSPAGE and estimated to $98 \%$. Its identity was confirmed by immunoblot using a mouse monoclonal antibody to $\mathrm{HCV}$ core protein (Affinity BioReagents).

\section{Mitochondrial Isolation}

This was performed according to the procedure of Korenaga et al. ${ }^{6}$ The mitochondrial fractions were prepared from livers of $\mathrm{C} 57 \mathrm{Bl} / 6$ mice fed the Lieber DeCarli control or ethanol diet for 3 weeks. Briefly, liver tissue was rinsed with ice-cold phosphate-buffered saline and lysed by 20 strokes in a Dounce homogenizer, in 40 $\mathrm{mmol} / \mathrm{L}$ Tris-HCl, $1 \mathrm{mmol} / \mathrm{L}$ EDTA, $150 \mathrm{mmol} / \mathrm{L} \mathrm{NaCl}$, ( $\mathrm{pH}$ 7.4). Homogenates were subjected to low-speed centrifugation, and mitochondrial pellets were obtained by centrifugation at $10,000 \mathrm{~g}$ for 10 minutes and then were resuspended in $200 \mathrm{mmol} / \mathrm{L}$ mannitol, $70 \mathrm{mmol} / \mathrm{L}$ EDTA, $10 \mathrm{mmol} / \mathrm{L}$ HEPES (pH 7.5). Alternatively, mito- chondria were prepared as described. ${ }^{19}$ Contamination of mitochondria with less than $5 \%$ of cytosol was detected. The latter was determined by the activity of lactate dehydrogenase in the mitochondrial preparation compared with that in cytosol.

\section{Microsome Isolation}

Microsomes were isolated from livers of control and ethanol-fed mice following the fractionation procedure previously published. ${ }^{19}$

\section{Proteasome Activity}

Proteasome chymotrypsin-like activity was detected in situ (intact cells) by measuring hydrolysis of the membrane-permeable substrate, methoxy-succinyl-pheleu-phe-7-amido-4-trifluoromethyl coumarin (MeO-SucFLF-AFC). ${ }^{20}$ To compare and combine the results of several experiments, for which we use different cell passages, proteasome activity expressed as nmol $\mathrm{AFC} / \mu \mathrm{g}$ DNA in treated samples was divided by proteasome activity in nmol AFC/ $\mu \mathrm{g}$ DNA in control sample, and this ratio was multiplied by $100 \%$. In vitro assay of chymotrypsin-like activity purified proteasome was performed using the fluorogenic substrate Suc-LLVY-AMC. Briefly, the latter reaction was run in black 96-well plates, at 200 $\mu \mathrm{L} /$ well, containing $0.1 \mathrm{~mol} / \mathrm{L}$ Tris- $\mathrm{HCl}(\mathrm{pH} 7.5)$ and 13 $\mu \mathrm{mol} / \mathrm{L}$ Suc-LLVY-AMC substrate. After 15 - to 60minute incubation at $37^{\circ} \mathrm{C}$, the reaction product, $\mathrm{AMC}$, was detected fluorometrically on a plate reader (Victor 3; Perkin Elmer, Shelton, CT), (excitation, $355 \mathrm{~nm}$; emission, $460 \mathrm{~nm}$ ). Enzyme specific activity is expressed as nmol AMC/mg protein.

\section{In Vitro Incubations}

Purified 20S proteasome $(50 \mu \mathrm{g}$ protein $/ \mathrm{mL})$ in $0.1 \mathrm{mmol} / \mathrm{L}$ Tris-HCl $(\mathrm{pH} 7.5)$ was incubated for 10 minutes with increasing quantities of core/mitochondrial mixture. The ratio of core protein to mitochondrial protein in the incubation mixture was always maintained at $1: 100,000$. Thus, the ratio of core protein to mitochondrial proteins used for these in vitro experiments was comparable with those reported in HCV core proteinexpressing mice. ${ }^{6}$ We tested the $20 \mathrm{~S}$ proteasome activity using 100,200 , or $300 \mathrm{pg}$ core protein using a corresponding amount of mitochondrial protein (ie, 10, 20, and $30 \mu \mathrm{g}$ mitochondrial protein, respectively) in the incubation mixture. The same mass quantities of microsomal proteins were also used. After incubation, the mixtures were assayed for proteasome chymotrypsin-like activity.

\section{Statistical Analyses}

Data are expressed as mean values \pm standard deviation. Multiple comparisons for significance were determined by 1-way ANOVA, using a Tukey post hoc test. Comparison between 2 groups used Student $t$ test. A probability value of .05 or less was considered significant. 


\section{Results}

\section{Differential Proteasome Activity in Core ${ }^{+}$ $\left(\right.$ tet $\left.^{-}\right)$and Core ${ }^{-}\left(\right.$tet $\left.^{+}\right)$Cells}

Proteasome activity was significantly higher in both CYP2E1-negative 191-20 cells and CYP2E1-positive L-14 cells that expressed core protein in the absence of tetracycline as compared with the same cells in the presence of tetracycline. Proteasome chymotrypsin-like activity was $20 \%$ higher in core-positive $191-20$ cells compared with core-negative 191-20 cells. This activity was $60 \%$ higher in the constitutively expressing CYP2E1 core-positive L-14 cells compared with the same cells that do not express core protein (Figure 1B). These results clearly indicated an association between HCV core expression and proteasome activity. Tetracycline by itself had no effect on proteasome activity. This was confirmed using the parental core nonexpressing Huh7 cells that were similarly treated with tetracycline (Figure $1 B$ ).

Because expression of $\mathrm{HCV}$ core protein has been shown to generate intracellular oxidants, ${ }^{7}$ we tested the effect of various antioxidants on in situ proteasome activity in both 191-20 and L-14 cells. The addition of glutathione ethyl ester (GSH-EE), N-acetyl cysteine, uric acid, diallyl sulfide (DAS), or catalase to the extracellular medium of core-protein cells caused a decrease in proteasome activity that approached the activity level in the core-negative cells (Figure $1 C$ and $D$ ).

\section{Differential Effects of Ethanol Treatment in 191-20 and L-14 Cells}

In core-negative and core-positive 191-20 cells, treatment with $50 \mathrm{mmol} / \mathrm{L}$ ethanol for 72 hours did not affect proteasome activity (data not shown). However, exposure of CYP2E1-positive L-14 cells to ethanol suppressed proteasome activity by $33 \%$ in the presence of core protein (Figure $2 A$ ). Suppression of proteasome activity by ethanol in core-positive cells was blocked by simultaneous exposure to DAS, catalase, or GSH-EE (Figure $2 B)$.

\section{Biphasic Response of 20S Proteasome to T-butyl Hydroperoxide}

To provide an explanation for the observed differential regulation of proteasome activity by core protein, we tested whether the proteasome activity is affected by various doses of the oxidant t-butyl hydroperoxide ( $t$ BOOH). Core-positive, CYP2E1-negative 191-20 cells were treated with increasing concentrations of $\mathrm{t}-\mathrm{BOOH}$ $(10 \mu \mathrm{mol} / \mathrm{L}$ to $100 \mu \mathrm{mol} / \mathrm{L})$ for 5 hours, and in situ proteasome activity was measured. Ten $\mathrm{mmol} / \mathrm{L} \mathrm{t}-\mathrm{BOOH}$ increased proteasome activity in these cells by $75 \%, 30$ $\mu \mathrm{mol} / \mathrm{L} \mathrm{t}-\mathrm{BOOH}$ had no significant effect, and 50 and $100 \mu \mathrm{mol} / \mathrm{L} \mathrm{t}$-BOOH completely abolished enzyme activity (Figure 3 ). We had previously reported a similar biphasic regulation of proteasome in HepG2 cells exposed to the peroxynitrite donor SIN-1, which elevated protea-
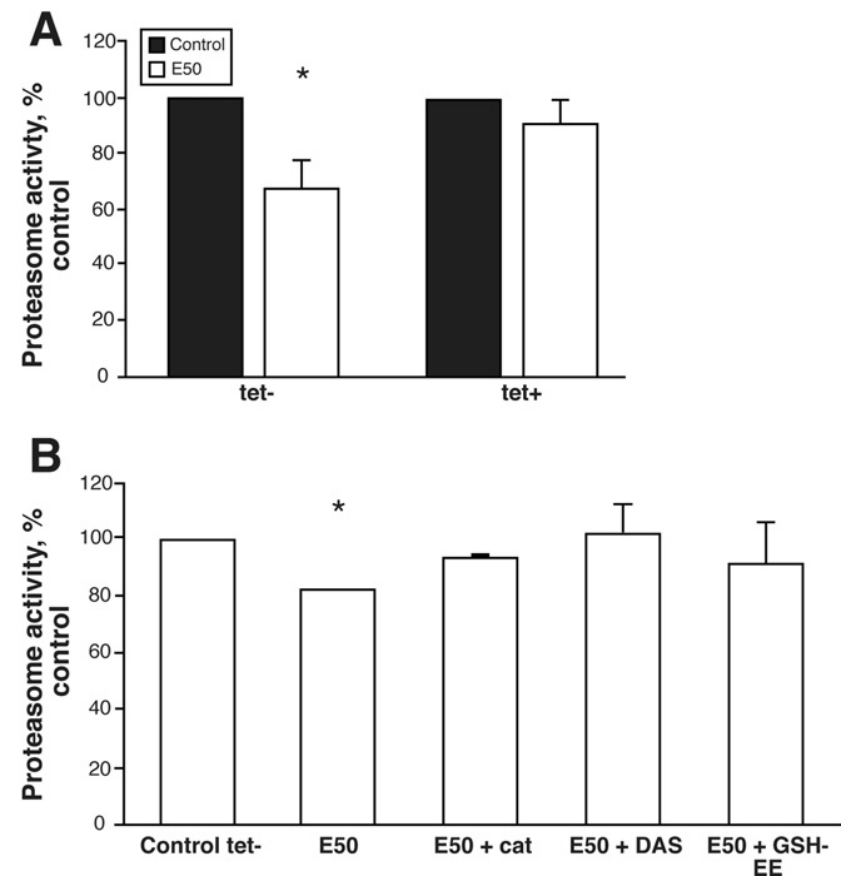

Figure 2. (A) Effects of ethanol on L-14 cells. Cells were treated or not with $50 \mathrm{mmol} / \mathrm{L}$ ethanol for 72 hours. Proteasome activity was measured by in situ assay. Data from 4 independent experiments are presented as percent of control proteasome activity in tetracyclineuntreated and -treated cells. ${ }^{*}$ ndicates a significant difference $(P<.05)$ between proteasome activity in control (untreated cells) and ethanoltreated cells. (B) Effects of ethanol on L-14 cells in the presence of glutathione precursors, GSH-EE and N-acetyl cysteine (NAC), and ethanol metabolism inhibitors. Tetracycline-untreated L-14 cells were exposed to $50 \mathrm{mmol} / \mathrm{L}$ ethanol in the presence or absence of catalase, DAS, or GSH-EE at the indicated concentrations for 72 hours. Proteasome activity was measured by in situ assay. Data from 3 independent experiments are presented as percent of control proteasome activity in ethanol-untreated L-14 cells. *Indicates a significant difference between control and treated cells.

some activity at low doses and decreased its in situ activity at high doses. ${ }^{21}$

\section{In Vitro Activation of Proteasome With Core Protein}

To determine whether core protein directly affects proteasome activity in vitro (in the absence of oxidants), we incubated purified $20 \mathrm{~S}$ proteasome with core protein, as detailed in the Materials and Methods section. The purity of core protein was confirmed (shown in Figure $4 A$ ). However, we utilized 2 different proteasome preparations. One preparation (Pr. 1) contained both $20 \mathrm{~S}$ proteasome as well as the proteasome activator PA28, as revealed by Western blot analysis (Figure $4 B$ ). The other preparation (Pr. 2) had undetectable levels of PA28 (Figure $4 B$ ). We observed that the core protein caused a dose-dependent activation of the proteasome only with Pr. 1 preparation and not with Pr. 2 (Figure 4C). Such activation was rather specific for core protein because the addition of the same mass of bovine serum albumin or 


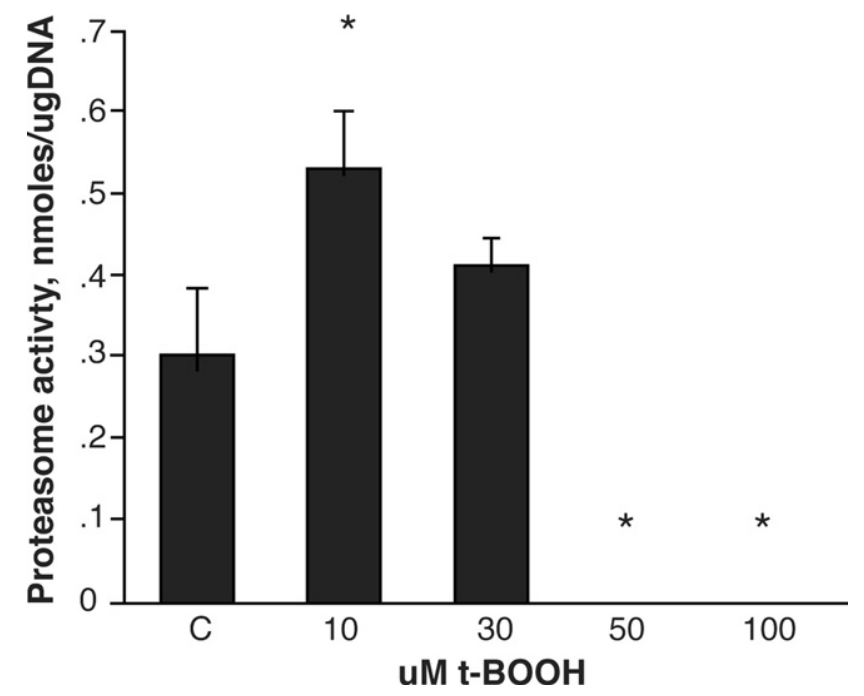

Figure 3. Effects of various concentrations of $\mathrm{t}-\mathrm{BOOH}$ on proteasome activity in core ${ }^{+} 191-20$ cells. Cells were exposed to indicated concentrations of $\mathrm{t}-\mathrm{BOOH}$ for 5 hours, and then proteasome activity was measured by in situ assay. Data from 2 experiments are presented as specific proteasome activity, nmol/ $\mu \mathrm{g}$ DNA. *Indicates a significant difference $(P<.05)$ between control and treated cells.

recombinant NS3 protein (Virogen, Inc, Watertown, MA) failed to activate Pr. 1 preparation (Figure 4C). The effect of $\mathrm{HCV}$ core protein on proteasome preparation was similar to the effect of commercially available HCV core protein (Virogen, Inc) on commercially available $20 \mathrm{~S}$ proteasome obtained from Boston Biochem (Figure 4C). Thus, Pr. 1 preparation was used in all subsequent in vitro incubations.

\section{Effects of Mitochondria and Microsomes on Proteasome Activation by Core Protein}

It has been reported that in vivo, HCV core protein associates with the mitochondrial membrane., 4 Therefore, we examined the effects of isolated mitochondria on the $20 \mathrm{~S}$ proteasome activity modulation by $\mathrm{HCV}$ core on the premise that the core protein might function in association with other mitochondrial components. Pr. 1 was incubated with core protein as well as mitochondrial preparations obtained from livers of control or ethanol-fed C57Bl/ 6 mice. Inclusion of $30 \mu \mathrm{g}$ mitochondrial protein in the incubation mixture (containing 300 pg core) enhanced the activation of proteasome by core protein up to 6.3-fold (Figure $5 A$ ). In contrast, a 3.2-fold increase in proteasome activation was observed when mitochondria fractions from ethanol-fed mice were used. This indicates a blunted response with mitochondria from ethanol-fed mice (Figure 5A). No differences were observed between freshly isolated and frozen mitochondria on core protein-induced proteasome activation. Furthermore, only mitochondria protein used at a $10-\mu \mathrm{g}$ level significantly enhanced the activating effect of recombinant PA28 $\alpha$, which, by itself, increased proteasome activity by 1.8 -fold (Figure $5 B$ ).
In cells, core protein is associated not only with mitochondria but also with the ER membrane. To determine the effects of ER preparations (ie, microsomes) on coremediated proteasome activation, we conducted similar experiments as with mitochondrial fractions. A 2.3-fold increase in proteasome activity was observed when microsomes from control mice were incubated in the presence of core protein and Pr. 1 proteosome preparation (Figure 5A). Microsomes combined with mitochondria caused a 7.4-fold elevation of proteasome activity. Proteasome activation was again attenuated when microsomes from ethanol-fed mice were used with core protein (1.5-fold stimulation). Moreover, there was no further elevation of proteasome activity when microsomes and

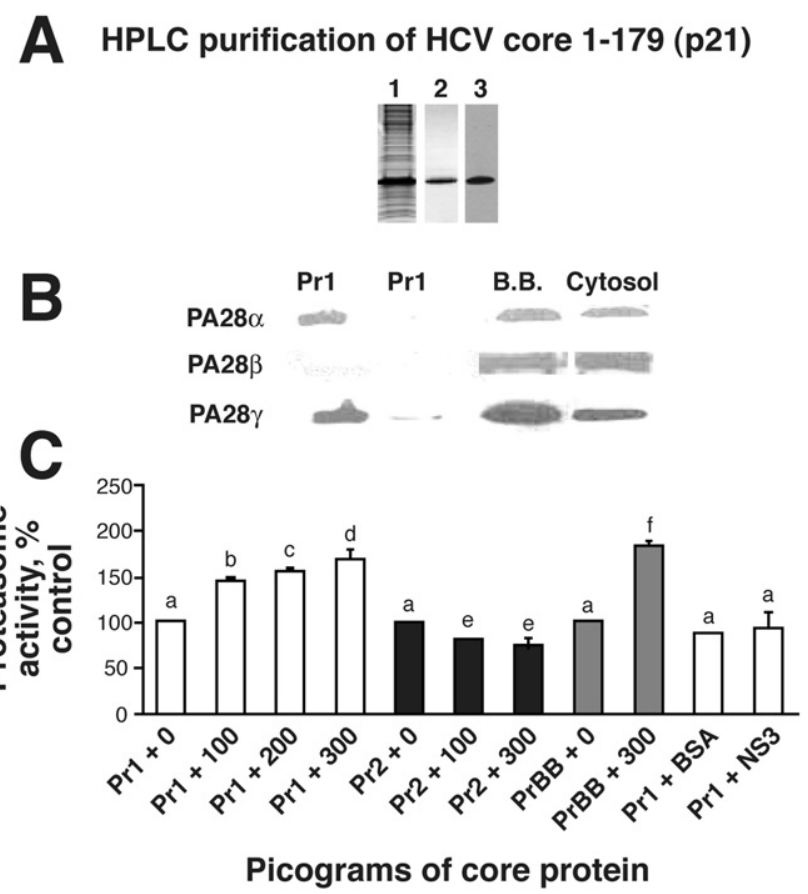

Figure 4. (A) HPLC purification of core protein. Samples were subjected to SDS-PAGE and visualized by coomassie blue stain (lanes 1 and 2) or immunoblot for core protein (lane 3). Lane 1: lysed bacterial cell pellet; lane 2: purified HCVC 179; lane 3: purified HCVC 179. (B) Expression of PA28 subunits in various proteasome preparations (Pr. 1, proteasome 1; Pr. 2, proteasome 2; BB, proteasome from Boston Biochem). A representative blot is presented for 2 proteasome preparations that were obtained as described then subjected to Western blot analysis. 20S proteasome preparations ( $\mathrm{Pr} .1$ and $\mathrm{Pr}$. 2) were probed for PA28 $\alpha, \beta$, and $\gamma$ using specific antibodies (Biomol International). BB proteasome preparations and crude cytosolic proteasome preparation were used as controls. (C) Effects of core protein on proteasome activity in 2 proteasome preparations. 20S proteasome (Pr. 1 and Pr. 2) preparations were incubated with 100,200, and 300 pg core protein for 5 minutes at $25^{\circ} \mathrm{C}$ and with $300 \mathrm{pg}$ bovine serum albumin or NS3 protein. Proteasome activity was then detected by Suc-LLVY-AMC hydrolysis. Data from 3 experiments are presented as percent of $20 \mathrm{~S}$ proteasome activity. As the control, exposure of commercial HCV core protein (Virogen, Inc) to commercial 20S proteasome (Boston Biochem) was used (Pr. 1, open bars; Pr. 2, solid bars; BB, shaded bars). Columns with different letters are significantly different from each other, and columns with the same letters are not. 

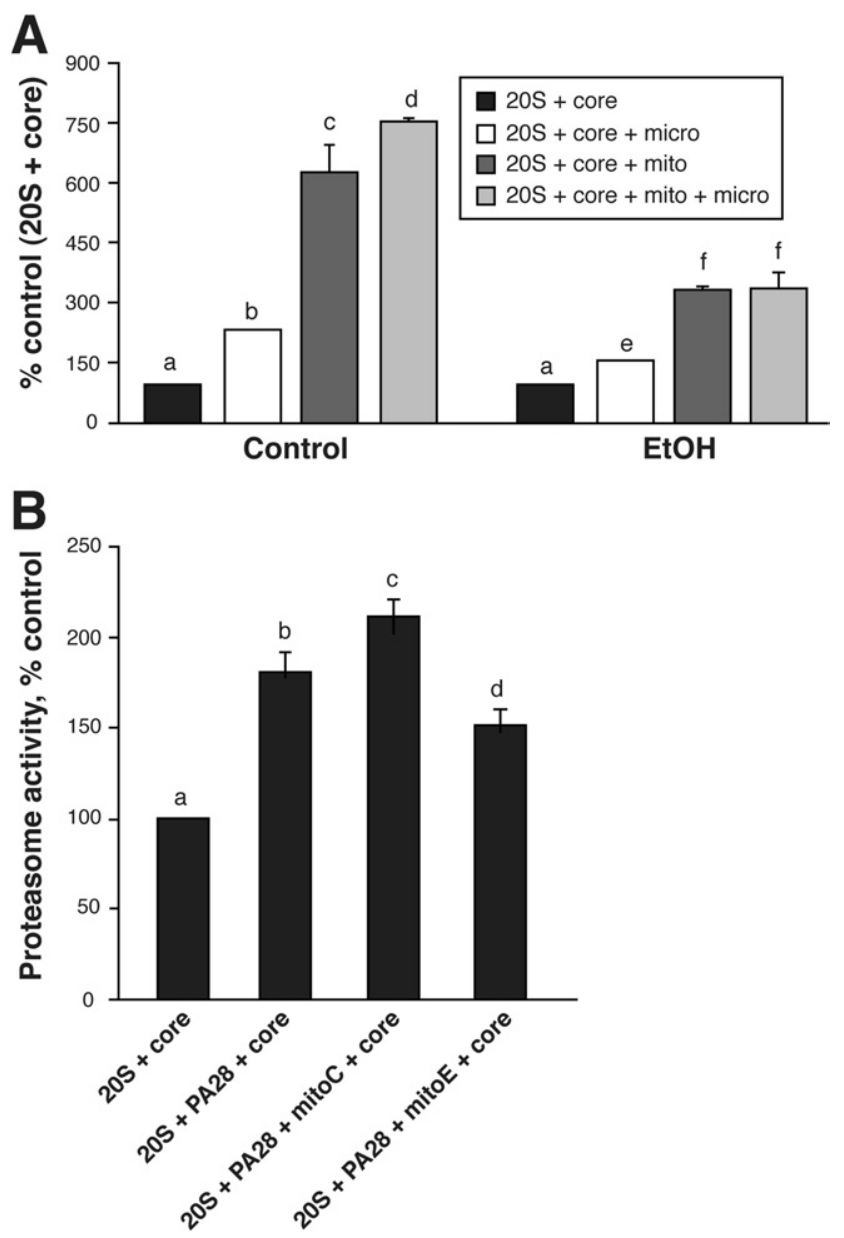

Figure 5. (A) The effects of mitochondria and microsomes on coreactivated 205 proteasome activity. Mitochondrial and microsome fractions were obtained from livers of control and ethanol-fed mice. 205 proteasome was incubated with 300 pg core protein and an equal mixture of mitochondrial and microsomal proteins (see Materials and Methods section). Proteasome activity was then assayed. Data from 3 experiments are expressed as percent of $20 \mathrm{~S}$ proteasome activity with core protein alone. Bar columns with different letters are significantly different from each other, and columns with the same letters are not. By themselves, mitochondria and microsomes possess little-to-no proteasome activity (not shown). (B) Effects of mitochondria + core on $20 \mathrm{~S}$ proteasome after addition of recombinant PA28 $\alpha$. 20S proteasome (Pr.1) was exposed to PA28 in the presence or absence of core protein and of mitochondria isolated from livers of control (MitoC) or ethanol-fed (MitoE) mice (100 pg core/10 $\mu \mathrm{g}$ mitochondria). Data from 3 experiments are expressed as percent of $20 \mathrm{~S}$ proteasome activity (without additions). Bar columns with different letters are significantly different from each other, and columns with the same letters are not.

mitochondria from ethanol-fed mice were combined with core protein (Figure 5A). Neither mitochondria nor microsomes by themselves possessed significant proteasome activity (not shown).

\section{Discussion}

HCV core protein is degraded by the ubiquitinproteasome pathway, and E6AP has been identified as the specific ubiquitin ligase that marks the protein for deg- radation. ${ }^{22,23}$ Here, we demonstrated that core protein also regulates proteasome activity, which potentially would influence protein catabolism in HCV-infected hepatocytes. Furthermore, this study identifies a dual mechanism of core-mediated proteasome activation via core protein-induced oxidant generation, as was revealed from our cell culture experiments and evidence of cross talk between core protein and PA28-20S complex supported by the cell-free studies.

As already demonstrated by others, $, 6,7$ 191-20 and L-14 cells and core-expressing or nonexpressing mice had differential levels of ROS production/GSH content in mitochondria. Furthermore, Otani et $\mathrm{al}^{7}$ showed that the ratio between pro- and antioxidative factors (ROS and GSH, respectively) is lowest in core-positive 191-20 cells, with a moderate increase in core-positive L-14 cells, followed by an increase in ethanol and/or t-BOOH-treated core-positive L-14 cells. Thus, in core-positive/CYP2E1negative cells, core protein caused predominant generation of oxidants in mitochondria, whereas, in CYP2E1expressing cells, oxidant generation was initiated by core protein both at the mitochondrial and the ER levels and was potentiated by ethanol treatment.

Here, we utilized the same cell lines, which were exposed (or not) to ethanol, to create varying gradations of oxidant stress. We presumed that the differential levels of oxidant stress differentially regulated the proteasome activity. To mimic this situation, we exposed core-positive 191-20 cells to various doses of the oxidant t-BOOH, which, at low doses, increased proteasome function, and at high doses suppressed proteasome activity. This findings was not limited to $\mathrm{t}-\mathrm{BOOH}$, and similar results were reported using various concentrations of hydrogen peroxide as well as the peroxynitrite donor SIN1 in HepG2 cells. $^{21,24}$

Here, we observed enhanced proteasome activity in both core-positive 191-20 and L-14 cells, with a much higher magnitude of proteasome activation in CYP2E1expressing L-14 cells. These results, taken together with previous reports of low to moderate ROS generation/ GSH depletion in core-positive 191-20 and L-14 cells, ${ }^{7}$ indicated that these levels of oxidative stress activate proteasome. This conjecture was confirmed by data that showed that treatment with GSH analogs/precursors reversed core-induced proteasome activation in both cell lines. In addition, inclusion of antioxidants (uric acid or catalase) or the CYP2E1 inhibitor DAS lowered proteasome activity in CYP2E1-positive/core-positive L-14 cells to approach the same levels in core-negative cells. However, when L-14 cells were exposed to ethanol (portending a much higher level of oxidant generation), proteasome activity was suppressed. Indeed, a reciprocal relationship between CYP2E1 expression and proteasome activity has been previously reported, ${ }^{10,25,26}$ and we have also shown a decline in proteasome function by ethanol exposure..$^{12,27}$ The mechanism of this decline in proteasome activity can 
be attributed, in part, to the inability of PA28 to activate the 20S enzyme when proteasome is heavily oxidatively modified, although low amounts of oxidants facilitate the 20S-PA28 interactions. ${ }^{21}$

However, even in the absence of oxidative stress, core protein was able to activate $20 \mathrm{~S}$ proteasome, which formed the complex with PA28 $\alpha$ and $\gamma$. This means that, in addition to indirect core-mediated regulation of proteasome activity via oxidant stress, the possibility of direct core-proteasome interactions cannot be excluded. To clarify whether core protein also affects proteasome function via direct protein-proteasome interactions, we used a cell-free system, in which proteasome is exposed to core protein in the absence of oxidative stress. We observed a link between activating effects of core protein only on $20 S$ proteasome copurified with PA28 subunits, indicating that core protein affected $20 \mathrm{~S}$ proteasome activity by facilitating its interaction with assembled PA28 $(\alpha, \beta$, and $\gamma$ subunits). In fact, $\mathrm{PA} 28 \alpha$, and to a lesser extent $\beta$, are known as classical activators of $20 \mathrm{~S}$ proteasome chymotrypsin-like activity in the cytosol, and $\gamma$ subunit regulates proteasome trypsin-like activity, mainly, in the nucleus. ${ }^{28,29}$ In our study, PA28-20S proteasome complex responded to core protein by increased chymotrypsin-like activity, whereas, as reported earlier, core protein forms a complex with PA28 $\gamma$ but not with PA28 $\alpha$ and $\beta .{ }^{30}$ However, even if core protein initially attaches to PA28 $\gamma$, we cannot exclude that $\gamma$ subunit subsequently activates $\alpha$ subunit in PA28-20S proteasome preparation, thereby increasing chymotrypsin-like proteasome activity. This core-induced proteasome activation was further enhanced by addition of exogenous recombinant PA28 $\alpha$.

In HCV-expressing cells, core protein is located between the outer mitochondrial membrane and the ER. ${ }^{6}$ To mimic this cellular interaction in a cell-free system, we measured whether proteasome activation by core protein was further modulated by mitochondria and/or microsomes. Each subcellular fraction, either alone or in combination, potentiated proteasome activation by core protein. The activating effect of mitochondria was not dependent on their structural integrity because both frozen and freshly isolated mitochondrial preparations equally enhanced core protein-mediated 20S proteasome activation. Therefore, proteasomal activation was likely the result of interactions between 20S-PA28 complex and specific mitochondrial protein(s), possibly, in/on the outer membrane. This is consistent with findings of others that core protein has a strong tendency to associate with various proteins, such as STAT1 and Jaks, affecting their functions. ${ }^{31,32}$ Interestingly, the cross talk between core-activated proteasome and mitochondria or/and microsomes was blunted in the presence of mitochondria or microsomes from ethanol-fed mice, indicating that ethanol-induced dysregulation of protein expression in these organelles may be attributed to their adduction by oxidants.
The nature of the putative proteasome-interacting protein(s) in mitochondria and ER is not clear. Heat shock proteins (HSP) are potential candidates for providing communication between mitochondria, microsomes, and the proteasome because the role of HSP in interactions between the microsomal enzyme CYP2E1 and the proteasome has been established. ${ }^{33}$ Mitochondria may also affect the activity of 20S-PA28 complex via interactions between mitochondrial HSP70 and PA28 because mitochondria express HSP70 $^{34}$ and the association between HSP70 and PA28 during substrate refolding has been reported. ${ }^{35}$

The physiologic and pathogenic relevance of proteasome activation by core protein is in an enhanced ability of proteasome to cleave the substrate proteins. Because some $\mathrm{HCV}$ proteins (such as NS5B as well as nuclear core protein) are targeted by proteasome, ${ }^{36}$ their rapid degradation may be favorable for HCV elimination. However, these proteins, in turn, form stable complexes with other important signaling proteins, thereby facilitating the removal of HCV-signaling factor complexes by proteasome. For example, in HCV protein-expressing cells, the depletion of STAT1, a signal transduction factor for interferons, may be potentially attributed to enhanced proteasome function as demonstrated by suppression of STAT1 disappearance in the presence of the proteasome inhibitor, MG132. ${ }^{37}$ Similarly, activation of proteasome by viral proteins leads to degradation of protective factors, as observed in other viral infections. ${ }^{38}$ However, even if core protein enhances proteasome activity, this may not result in tremendously increased generation of peptides for MHC class I-restricted antigen presentation because the most antigen-processing enzymes (including proteasome) are activated by interferon, and, to be effective, peptide processing requires unaltered interferon signaling, whereas STAT1 is degraded by the proteasome. If core-positive/CYP2E1-expressing liver cells are exposed to ethanol, ethanol metabolism suppresses proteasome activity. This may prevent the degradation of the "protective" proteins, such as STAT1, but will ultimately block STAT1 phosphorylation..$^{27}$ The processing of viral peptides for antigen presentation by liver cells will be further suppressed because, in this case, ethanol metabolism not only suppresses proteasome-dependent cleavage of antigenic peptides but also prevents interferon signaling by altering STAT1 phosphorylation. The outcomes of core-induced proteasome activation and the suppressing effects of ethanol exposure for innate and adaptive immunity, as well as the identification of proteins involved in HCV core-proteasome-mitochondrion-ER interactions, will be the subject of future investigations. A proposed mechanism of core-proteasome interactions in liver cells is depicted in Figure 6.

In summary, $\mathrm{HCV}$ core protein enhanced $20 \mathrm{~S}$ proteasome activity directly, by facilitating interactions among $20 \mathrm{~S}$ proteasome, PA28, and mitochondria/microsomes and, indirectly, via generation of low levels of oxidants. Elevated oxidant generation by ethanol metabolism and disruption of core-20S-PA28-mitochondrial interactions 


\section{Low oxidative stress (no EtOH)}

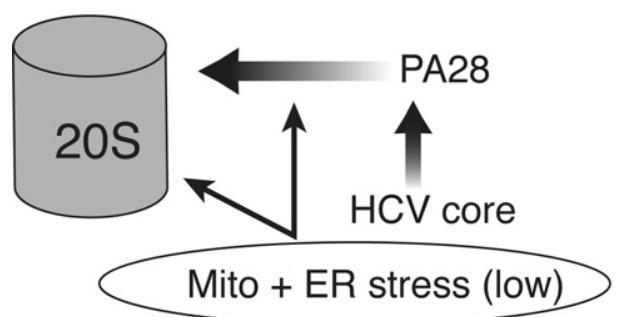

\section{High oxidative stress (EtOH)}

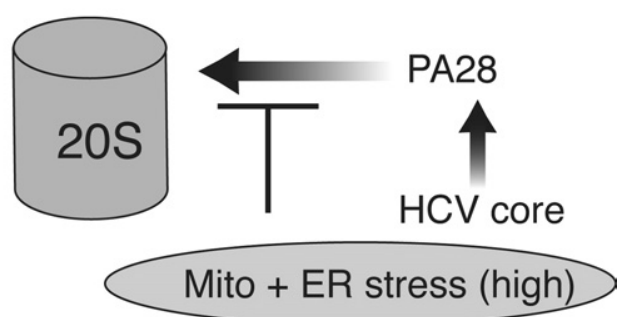

Figure 6. Proposed mechanism of regulation of proteasome function by core protein in liver cells. Core protein stimulates proteasome, directly facilitating PA28-20S interaction. These effects are potentiated by mitochondrial and microsomal protein(s), which further enhance proteasome activation by core protein. In addition, HCV core protein induces a low level of oxidative stress and also increases proteasome activity. Treatment of core-expressing CYP2E1 ${ }^{+}$cells by ethanol disrupts interactions between $20 S$ proteasome-PA28 complex and mitochondria and creates a high level of oxidative stress, which suppresses proteasome activity.

ultimately results in reduced liver proteasome activity that may influence the propagation of HCV clinical course in alcoholic patients.

\section{References}

1. Ulrich HD, Vogel S, Davies AA. SUMO keeps a check on recombination during DNA replication. Cell Cycle 2005;4:1699-1702.

2. Kim TK, Maniatis T. Regulation of interferon- $\gamma$-activated STAT1 by the ubiquitin-proteasome pathway. Science 1996;273:17171719.

3. Rock KL, York IA, Saric T, et al. Protein degradation and the generation of MHC class I-presented peptides. Adv Immunol 2002;80:1-70.

4. Wen F, Abdalla MY, Aloman C, et al. Increased prooxidant production and enhanced susceptibility to glutathione depletion in HepG2 cells co-expressing HCV core protein and CYP2E1. J Med Virol 2004;72:230-240.

5. Wang T, Weinman SA. Causes and consequences of mitochondrial reactive oxygen species generation in hepatitis C. J Gastroenterol Hepatol 2006;21(Suppl 3):S34-S37.

6. Korenaga M, Okuda M, Otani K, et al. Mitochondrial dysfunction in hepatitis C. J Clin Gastroenterol 2005;39:S162-S166.

7. Otani K, Korenaga M, Beard MR, et al. Hepatitis C virus core protein, cytochrome P450 2E1, and alcohol produce combined mitochondrial injury and cytotoxicity in hepatoma cells. Gastroenterology 2005;128:96-107.

8. Osna NA, Clemens DL, Donohue TM Jr. Interferon $\gamma$ enhances proteasome activity in recombinant Hep G2 cells that express cytochrome P4502E1: modulation by ethanol. Biochem Pharmacol 2003;66:697-710.

9. Bardag-Gorce F, Li J, French BA, et al. The effect of ethanolinduced CYP2E1 on proteasome activity: the role of 4-hydroxynonenal. Exp Mol Pathol 2005;78:109-115.

10. Kessova IG, Cederbaum Al. The effect of CYP2E1-dependent oxidant stress on activity of proteasomes in HepG2 cells. J Pharmacol Exp Ther 2005;315:304-312.

11. Donohue TM, Osna NA, Clemens DL. Recombinant Hep G2 cells that express alcohol dehydrogenase and cytochrome P450 2E1 as a model of ethanol-elicited cytotoxicity. Int J Biochem Cell Biol 2006;38:92-101.

12. Osna NA, White RL, Todero S, et al. Ethanol-induced oxidative stress suppresses generation of peptides for antigen presentation by hepatoma cells. Hepatology 2007;45:53-61.

13. Nevins $\mathrm{CL}$, Malaty $\mathrm{H}$, Velez ME, et al. Interaction of alcohol and hepatitis $\mathrm{C}$ virus infection on severity of liver disease. Dig Dis Sci 1999;44:1236-1242.
14. Khan KN, Yatsuhashi H. Effect of alcohol consumption on the progression of hepatitis $\mathrm{C}$ virus infection and risk of hepatocellular carcinoma in Japanese patients. Alcohol Alcohol 2000;35: 286-295.

15. Beyette JR, Hubbell T, Monaco JJ. Purification of $20 \mathrm{~S}$ proteasomes. Methods Mol Biol 2001;156:1-16.

16. Chu-Ping M, Slaughter CA, DeMartino GN. Purification and characterization of a protein inhibitor of the $20 \mathrm{~S}$ proteasome (macropain). Biochim Biophys Acta 1992;1119:303-311.

17. Kunkel M, Lorinczi M, Rijnbrand R, et al. Self-assembly of nucleocapsid-like particles from recombinant hepatitis $\mathrm{C}$ virus core protein. J Virol 2001;75:2119-2129.

18. Brown EA, Zhang H, Ping LH, et al. Secondary structure of the 5' nontranslated regions of hepatitis $\mathrm{C}$ virus and pestivirus genomic RNAs. Nucleic Acids Res 1992;20:5041-5045.

19. Donohue TM Jr, McVicker DL, Kharbanda KK, et al. Ethanol administration alters the proteolytic activity of hepatic lysosomes. Alcohol Clin Exp Res 1994;18:536-541.

20. Hamel FG, Bennett RG, Harmon KS, et al. Insulin inhibition of proteasome activity in intact cells. Biochem Biophys Res Commun 1997;234:671-674.

21. Osna NA, Haorah J, Krutik VM, et al. Peroxynitrite alters the catalytic activity of rodent liver proteasome in vitro and in vivo. Hepatology 2004;40:574-582.

22. Suzuki R, Tamura K, Li J, et al. Ubiquitin-mediated degradation of hepatitis $C$ virus core protein is regulated by processing at its carboxyl terminus. Virology 2001;280:301-309.

23. Shirakura M, Murakami K, Ichimura T, et al. E6AP ubiquitin ligase mediates ubiquitylation and degradation of hepatitis $\mathrm{C}$ virus core protein. J Virol 2007;81:1174-1185.

24. Grune T, Klotz LO, Gieche J, et al. Protein oxidation and proteolysis by the nonradical oxidants singlet oxygen or peroxynitrite. Free Radic Biol Med 2001;30:1243-1253.

25. Perez MJ, Cederbaum Al. Proteasome inhibition potentiates CYP2E1-mediated toxicity in HepG2 cells. Hepatology 2003;37: 1395-1404.

26. Bardag-Gorce F, Yuan QX, Li J, et al. The effect of ethanol-induced cytochrome p4502E1 on the inhibition of proteasome activity by alcohol. Biochem Biophys Res Commun 2000;279:23-29.

27. Osna NA, Clemens DL, Donohue TM Jr. Ethanol metabolism alters interferon $\gamma$ signaling in recombinant HepG2 cells. Hepatology 2005;42:1109-1117.

28. Brychcy M, Kuckelkorn U, Hausdorf G, et al. Anti-20S proteasome autoantibodies inhibit proteasome stimulation by proteasome activator PA28. Arthritis Rheum 2006;54:2175-2183. 
29. Li J, Gao X, Ortega J, et al. Lysine 188 substitutions convert the pattern of proteasome activation by REG $\gamma$ to that of REGs $\alpha$ and ß. EMBO J 2001;20:3359-3369.

30. Moriishi K, Okabayashi T, Nakai K, et al. Proteasome activator PA28 $\gamma$-dependent nuclear retention and degradation of hepatitis C virus core protein. J Virol 2003;77:10237-10249.

31. Lin W, Kim SS, Yeung E, et al. Hepatitis C virus core protein blocks interferon signaling by interaction with the STAT1 SH2 domain. J Virol 2006;80:9226-9235.

32. Hosui A, Ohkawa $\mathrm{K}$, Ishida $\mathrm{H}$, et al. Hepatitis $\mathrm{C}$ virus core protein differently regulates the JAK-STAT signaling pathway under interleukin-6 and interferon- $\gamma$ stimuli. J Biol Chem 2003;278:2856228571.

33. Goasduff T, Cederbaum Al. CYP2E1 degradation by in vitro reconstituted systems: role of the molecular chaperone hsp90. Arch Biochem Biophys 2000;379:321-330.

34. Lu X, Michaud C, Orlowski M. Heat shock protein-90 and the catalytic activities of the 205 proteasome (multicatalytic proteinase complex). Arch Biochem Biophys 2001;387:163-171.

35. Minami $Y$, Kawasaki $H$, Minami $M$, et al. A critical role for the proteasome activator PA28 in the Hsp90-dependent protein refolding. J Biol Chem 2000;275:9055-9061.

36. Munakata $\mathrm{T}$, Liang $\mathrm{Y}$, Kim $\mathrm{S}$, et al. Hepatitis $\mathrm{C}$ virus induces E6AP-dependent degradation of the retinoblastoma protein. PLoS Pathog 2007;3:1335-1347.
37. Lin W, Choe WH, Hiasa $Y$, et al. Hepatitis C virus expression suppresses interferon signaling by degrading STAT1. Gastroenterology 2005;128:1034-1041.

38. Hampson L, Kitchener HC, Hampson IN. Specific HIV protease inhibitors inhibit the ability of HPV16 E6 to degrade p53 and selectively kill E6-dependent cervical carcinoma cells in vitro. Antivir Ther 2006;11:813-825.

Received September 21, 2007. Accepted February 21, 2008.

Address requests for reprints to: Natalia Osna, MD, PhD, Liver Study Unit, Research Service (151), VA Medical Center, 4101 Woolworth Ave, Omaha, Nebraska 68105. e-mail: nosna@unmc.edu; fax: (402) 4490604.

Supported by the National Institute on Alcohol Abuse and Alcoholism (NIAAA), grants 5R21 AA015379-02 and AA012863, and, in part, by AA09384 and by Medical Research Funds from the Department of Veteran Affairs.

The authors thank Sandra Todero and John Evans for excellent technical assistance; Tiana Curry-McCoy for providing proteasome 2 preparation; Dr George DeMartino, University of Texas Southwestern Medical Center, Dallas, Texas, for providing recombinant PA28 $\alpha$; and Dr Kusum Kharbanda, VA Medical Center, Omaha, for fruitful discussion of the manuscript.

Conflicts of interest: No conflicts of interest exist. 